\title{
Biomass Related Highly Porous Metal Free Carbon for Gas Storage and Electrocatalytic Applications
}

\author{
Samantha K. Samaniego Andrade ${ }^{1}$, István Bakos ${ }^{2}$, Gábor Dobos ${ }^{3}$, Attila Farkas ${ }^{4}$, Gábor Kiss ${ }^{3}$, \\ Szilvia Klébert ${ }^{2}\left(\mathbb{D}\right.$, János Madarász ${ }^{5}$ and Krisztina László ${ }^{1, *(D)}$ \\ 1 Department of Physical Chemistry and Materials Science, Budapest University of Technology and Economics, \\ 1521 Budapest, Hungary; ssamaniegoandrade@edu.bme.hu \\ 2 Research Centre for Natural Sciences, Institute of Materials and Environmental Chemistry, Eötvös Loránd \\ Research Network, Magyar tudósok körútja 2, 1117 Budapest, Hungary; bakos.istvan@ttk.hu (I.B.); \\ klebert.szilvia@ttk.hu (S.K.) \\ 3 Department of Atomic Physics, Budapest University of Technology and Economics, 1521 Budapest, Hungary; \\ dobosg@eik.bme.hu (G.D.); gkiss@mail.bme.hu (G.K.) \\ 4 Department of Organic Chemistry and Technology, Budapest University of Technology and Economics, \\ 1521 Budapest, Hungary; farkas.attila@vbk.bme.hu \\ 5 Department of Inorganic and Analytical Chemistry, Budapest University of Technology and Economics, \\ 1521 Budapest, Hungary; madarasz.janos@vbk.bme.hu \\ * Correspondence: laszlo.krisztina@vbk.bme.hu
}

Citation: Andrade, S.K.S.; Bakos, I.; Dobos, G.; Farkas, A.; Kiss, G.; Klébert, S.; Madarász, J.; László, K. Biomass Related Highly Porous Metal Free Carbon for Gas Storage and Electrocatalytic Applications. Materials 2021, 14, 3488. https:// doi.org/10.3390/ma14133488

Academic Editors: Pasquale Fernando Fulvio and Mihkel Koel

Received: 18 May 2021

Accepted: 18 June 2021

Published: 23 June 2021

Publisher's Note: MDPI stays neutral with regard to jurisdictional claims in published maps and institutional affiliations.

Copyright: (C) 2021 by the authors Licensee MDPI, Basel, Switzerland. This article is an open access article distributed under the terms and conditions of the Creative Commons Attribution (CC BY) license (https:// creativecommons.org/licenses/by/ $4.0 /)$.

\begin{abstract}
In this paper we report the synthesis of a N, S co-doped metal free carbon cryogel obtained from a marine biomass derived precursor using urea as nitrogen source. Natural carrageenan intrinsically contains $\mathrm{S}$ and inorganic salt. The latter also serves as an activating agent during the pyrolytic step. The overall 11.6 atomic \% surface heteroatom concentration comprises 5\% O, 4.6\% N and $1 \% \mathrm{~S}$. The purified and annealed final carbon (CA) has a hierarchical pore structure of micro-, meso- and macropores with an apparent surface area of $1070 \mathrm{~m}^{2} / \mathrm{g}$. No further treatment was applied. The gas adsorption potential of the samples was probed with $\mathrm{H}_{2}, \mathrm{CO}_{2}$ and $\mathrm{CH}_{4}$, while the electrocatalytic properties were tested in an oxygen reduction reaction. The atmospheric $\mathrm{CO}_{2}$ and $\mathrm{CH}_{4}$ storage capacity at $0{ }^{\circ} \mathrm{C}$ in the low pressure range is very similar to that of HKUST- 1 , with the $\mathrm{CO}_{2} / \mathrm{CH}_{4}$ selectivity below 20 bar, even exceeding that of the MOF, indicating the potential of CA in biogas separation. The electrocatalytic behavior was assessed in an aqueous $\mathrm{KOH}$ medium. The observed specific gravimetric capacitance $377 \mathrm{~F} / \mathrm{g}$ was exceeded only in B, N dual doped and/or graphene doped carbons from among metal free electrode materials. The CA electrode displays almost the same performance as a commercial $20 \mathrm{wt} \% \mathrm{Pt} / \mathrm{C}$ electrode. The oxygen reduction reaction (ORR) exhibits the 4-electron mechanism. The 500-cycle preliminary stability test showed only a slight increase of the surface charge.
\end{abstract}

Keywords: N, S co-doped carbon; gas storage; electrocatalysis; oxygen reduction reaction; ORR

\section{Introduction}

A sustainable answer to the continuously growing demand for new carbon sources in energy storage or energy conversion applications lies in the exploitation of the potential of renewable biomass. The estimated carbon content in the overall biomass composition of the biosphere is $\approx 550$ gigatonnes and is distributed among various segments of life [1]. While the lignocellulosic biomass of agricultural origin has been used as a carbon precursor for a long time, the potential of the enormous quantity of marine biomass is far from being fully explored [2]. Carrageenan is a natural polysaccharide extracted from a red seaweed species (Rhodophyceae) with water or aqueous alkali. The global carrageenan industry was valued at USD 762.35 million by 2013 [3]. Regarding its chemical structure, carrageenan is a sulfated polygalactan with a content of $25-30 \%$ ester-sulfate groups; it is formed by alternating units of D-galactose and 3,6-anhydro-galactose (3,6-AG) connected by $\alpha-1,3$ 
and $\beta-1,4$-glycosidic linkage [4]. Commercial carrageenans are sold in the form of stable sodium, potassium, and calcium salts or as a mixture of them. Therefore, the sugar units in the chemical structure and the associated cations jointly determine the properties of the carrageenan [5]. Thus, the various species of carrageenans, like other natural carbon precursors, have the advantage that they contain heteroatoms that are preserved as dopants in the developing carbon matrix. Their inorganic salt content is beneficial during their conversion to highly porous carbon, and plays similar roles as chemical activating agents, e.g., $\mathrm{KOH}$ [6]. The catalytic role played by inorganic salts in pyrolysis has been recently discussed by Zhao et al. [7]. Another marine biomass, green algae, was used recently as a precursor for carbon materials with high electrocatalytic activity by Ilnicka et al. [8]. In carbon manufacturing, polymer precursors are especially preferred when carbon with low inorganic impurities is needed. Polyethyleneterephthalate (PET) might be a promising precursor. For its wide commercial application, its conversion to activated carbon also offers a way to reduce the volume of solid polymer waste [9].

The enhanced (electro)catalytic activity of metal free nanostructured carbons is attributed to the presence of heteroatoms (e.g., B, N, O, P, S) and various induced defects. A current review by Zhang et al. summarizes the recent advances in this field, particularly emphasizing the synergistic effects of doping and defects [10]. Sulphur is naturally present in carrageenan and is expected to be saved at least to some extent during its conversion to carbon. Although it has almost the same electronegativity (2.58) as carbon (2.55) the electrocatalytic activity of S-doped graphene was found to be superior to pristine graphene, owing to the electronic spin density of carbon atoms, especially those located on the edges [11,12]. It was shown that in oxygen reduction reactions (ORR) thiophenic sulfur compounds play an important role in withdrawing oxygen from electrolytes and fostering its physical adsorption in small carbon pores. Larger sulfur groups (sulfoxide, sulfones, and sulfonic acids) located in the surface of mesopores favoured access of the electrolyte with dissolved oxygen into the pore system [13,14]. Recently we showed that nitrogen atoms incorporated into carbon materials significantly increase the catalytic and electrocatalytic activity of high surface area carbon materials [15-17]. The improved catalytic performance of $\mathrm{N}$-doped carbon materials results from the redistribution of the charge density of adjacent $\mathrm{C}$ atoms, due to the electronegativity differences between nitrogen (3.04), and carbon atoms (2.55) (Pauling scale) [18]. The role of nitrogen atoms with different bonding states in the enhanced ORR activity is most often attributed to the graphitic and/or pyridinic nitrogen atoms [19]. N, S co-doped carbon materials have displayed promising electrochemical performances due to the synergistic effect between $\mathrm{N}$ and $\mathrm{S}$ atoms. Such materials are being investigated for their use in sodium-ion and lithium-ion batteries [20,21], electrocatalysis [22], and supercapacitors [23,24]. Recent DFT calculations revealed that dual S and $\mathrm{N}$ doping leads to the redistribution of spin and charge densities and thus to a large number of carbon atom active sites [25].

Besides the advantages of heteroatom doping, de Falco et al. demonstrated the additional benefit of the suitable pore structure in the ORR. The synergy of ultramicropores and hydrophobic surface rich in ether groups and/or electrons enhances the electrocatalytic efficiency of carbon materials and may result in an ORR performance similar to that measured on $\mathrm{Pt} / \mathrm{C}$ with a 4 electron transfer mechanism [26].

$\mathrm{N}$ or/and $\mathrm{S}$ doping also enhances the adsorption performance for $\mathrm{H}_{2}, \mathrm{CH}_{4}$, and $\mathrm{CO}_{2}$ [27]. They concluded that hydrogen adsorption is mainly related to the specific surface area, while the adsorption of $\mathrm{CO}_{2}$ is significantly influenced by sulfur doping. $\mathrm{N}$ doping is particularly efficient in promoting the uptake of $\mathrm{CO}_{2}$ [28]. It was reported recently that $\mathrm{O}, \mathrm{N}, \mathrm{S}$ doped carbon $(7.19 \mathrm{at} \% \mathrm{O}, 4.15 \mathrm{at} \% \mathrm{~N}$ and $1.01 \mathrm{at} \% \mathrm{~S})$ may adsorb more hydrogen gas at $-196{ }^{\circ} \mathrm{C}$ than most reported porous carbons, covalent organic frameworks (COFs) or metal organic frameworks (MOFs) [29]. The same authors also pointed out that the sulfonyl group is the one with the highest potential to adsorb $\mathrm{H}_{2}$.

In this paper we report the synthesis of a N, $\mathrm{S}$ co-doped carbon aerogel obtained from marine biomass. While $S$ is intrinsic in carrageenan, urea was added as a nitrogen source. 
The application potential of this carbon was tested in electrocatalysis and in the adsorption of environmentally relevant gases.

\section{Materials and Methods}

\subsection{Synthesis}

l-carrageenan powder and urea beads (98\%) were bought from Sigma-Aldrich (Budapest, Hungary). The commercial grade, Type II ı-carrageenan precursor contained $4-6 \%$ potassium, $2-4 \%$ calcium, and $1-2 \%$ sodium. The cryogel samples were synthetized according to the method of Li et al. [30]. Briefly, $4 \mathrm{~g}$ urea was dissolved in $200 \mathrm{~mL}$ of distilled water and warmed to $80^{\circ} \mathrm{C} .4 \mathrm{~g}$ of $\mathrm{t}$-carrageenan was added to the solution and stirred for $1 \mathrm{~h}$. l-carrageenan contains about 28 to $30 \%$ ester sulfate and its 3,6-anhydro-galactose content is $25-30 \%$ (Figure 1). Due to its strongly anionic half-ester sulfate groups it readily formed a hydrogel in the presence of the potassium and calcium ions. After freeze drying, the dry polymer aerogel (PA) was obtained with a yield of $93 \%$.

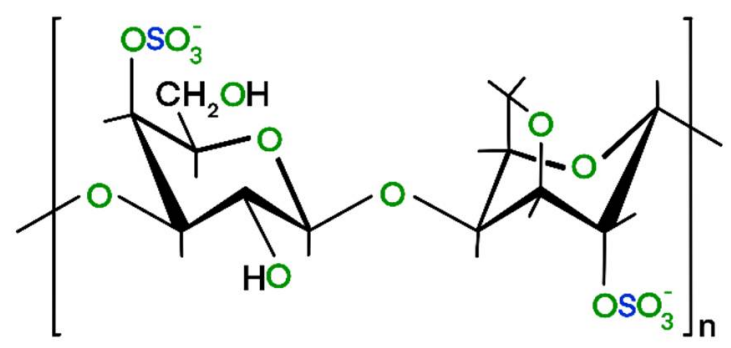

Figure 1. The chemical structure of a monomer unit of t-carrageenan.

PA was first carbonized in a rotary quartz reactor at $700{ }^{\circ} \mathrm{C}$ in a dry $\mathrm{N}_{2}$ atmosphere, providing a raw carbon aerogel (CR) with a yield of $10 \%$. After removing the inorganic impurities with aqueous $1.0 \mathrm{M} \mathrm{HCl}$ (yield 53\%), the washed sample (CW) was annealed in argon flow at $1000{ }^{\circ} \mathrm{C}$ for $1 \mathrm{~h}$, resulting in the annealed carbon sample (CA) with an overall yield of $2.4 \%$.

\subsection{Characterization Methods}

Low temperature $\left(-196.15^{\circ} \mathrm{C}\right)$ nitrogen adsorption measurements were performed after $24 \mathrm{~h}$ degassing at $110{ }^{\circ} \mathrm{C}$ on a NOVA 2000e (Quantachrome, Boynton Beach, FL, USA) automatic volumetric instrument. The apparent surface area $S_{B E T}$ was determined using the Brunauer-Emmett-Teller (BET) model [31]. A pore volume $V_{0.98}$ was estimated from the amount of vapor adsorbed at $p / p_{0}=0.98$, assuming that the adsorbed gas was present as liquid $\mathrm{N}_{2}$. The Dubinin-Radushkevich (DR) plot [32] was used to calculate the micropore volume $V_{\text {micro }}$. The pore size distribution in the micro and mesopore regions was computed by Quenched Solid Density Functional Theory (QSDFT) [33]. Evaluation of the primary adsorption data was performed with the Quantachrome ASiQwin software (version 3.0). Scanning electron microscopic (SEM) images of the gold coated samples were taken by a JEOL JSM 6380LA (Jeol Ltd., Tokyo, Japan). Elemental mapping was performed by the energy dispersive X-ray spectroscopy (EDS) option of the same instrument.

Powder X-ray diffractograms (XRD) were obtained in the range $2 \theta=10-130^{\circ}$ with an $X^{\prime}$ Pert Pro MPD (PANalytical Bv., Almelo, The Netherlands) X-ray diffractometer using an $\mathrm{X}^{\prime}$ celerator type detector and monochromatic $\mathrm{Cu} \mathrm{K} \alpha$ radiation with a $\mathrm{Ni}$ filter foil $(\lambda=1.5406 \AA)$ at $40 \mathrm{keV}$ and $30 \mathrm{~mA}$.

Raman spectra were obtained using a LabRAM (Horiba Jobin Yvon) instrument. The laser source was a $\lambda=532 \mathrm{~nm} \mathrm{Nd-YAG} \mathrm{(laser} \mathrm{power} \mathrm{at} \mathrm{the} \mathrm{focal} \mathrm{point} \mathrm{was} 15 \mathrm{~mW}$ ). A 0.6 OD filter was used to reduce the power of the beam. Parameter optimization and data analysis were performed with LabSpec 5 software. Fourier-transform infrared (FTIR) spectra were collected on an attenuated total reflection Fourier-transform infrared Tensor 
37 spectrophotometer (ATR-FTIR, Bruker) with a Specac Golden Gate ATR unit, and are shown here after background correction.

The surface chemical composition was studied by X-ray photoelectron spectra (XPS) using a Thermo Fisher XR4 twin anode X-ray source (Thermo Scientific, Paisley, UK) and a Specs Phoibos 150 hemispherical electron energy analyzer with an MCD9 detector (SPECS Surface Nano Analysis GmbH, Berlin, Germany). The MgK $\alpha$ radiation employed $(1253.6 \mathrm{eV})$ was not monochromated. A Gaussian-Lorentzian function mixed set was used to fit the peaks on each spectrum after subtracting Shirley-type backgrounds using CasaXPS.

The electrocatalytic tests were performed using a glassy carbon (GC) rotating disc electrode (RDE, Pine Research Instrumentation, Durham, NC, USA) and a rotating ringdisc electrode (RRDE) (GC disc and Pt ring). The ink for the working electrodes was prepared by dispersing $2 \mathrm{mg}$ powdered carbon (CA) in a mixture of $1.6 \mathrm{~mL}$ MilliQ water, $0.4 \mathrm{~mL}$ isopropyl alcohol and $8 \mu \mathrm{L} 5 \% \mathrm{Nafion}^{\circledR}$ solution. After $30 \mathrm{~min}$ sonication the ink was pipetted onto the dry mirror-polished GC and dried at room temperature. The loading was $100 \mu \mathrm{g} / \mathrm{cm}^{2}$. Measurements were implemented in $0.1 \mathrm{M} \mathrm{KOH}$ electrolyte using three-electrode systems with a hydrogen electrode as reference and a $\mathrm{Pt}$ wire as the counter electrode in a three-compartment PFTE cell (Figure S1). All potentials are given in the Reversible Hydrogen Electrode (RHE) scale. A detailed description is given in reference [16].

Carbon dioxide and methane isotherms were measured at $0{ }^{\circ} \mathrm{C}$ up to atmospheric pressure with an AUTOSORB-1 (Quantachrome, Boynton Beach, FL, USA) computercontrolled analyzer. An Autosorb 1C (Quantachrome, Boynton Beach, FL, USA) static volumetric instrument was used to perform hydrogen sorption experiments with high purity hydrogen $(99.999 \%)$ at $-196^{\circ} \mathrm{C}$.

\section{Results and Discussion}

\subsection{Development of the Morphology during the Synthesis}

Low temperature $\left(-196{ }^{\circ} \mathrm{C}\right)$ nitrogen adsorption isotherms of the carbon samples at different stages of the synthesis are presented in Figure 2a. According to the latest IUPAC classification, the three isotherms are of composite Type IV +Type II with a H4 hysteresis loop with the expected sharp step-down at $p / p_{0}=0.45$ [34].

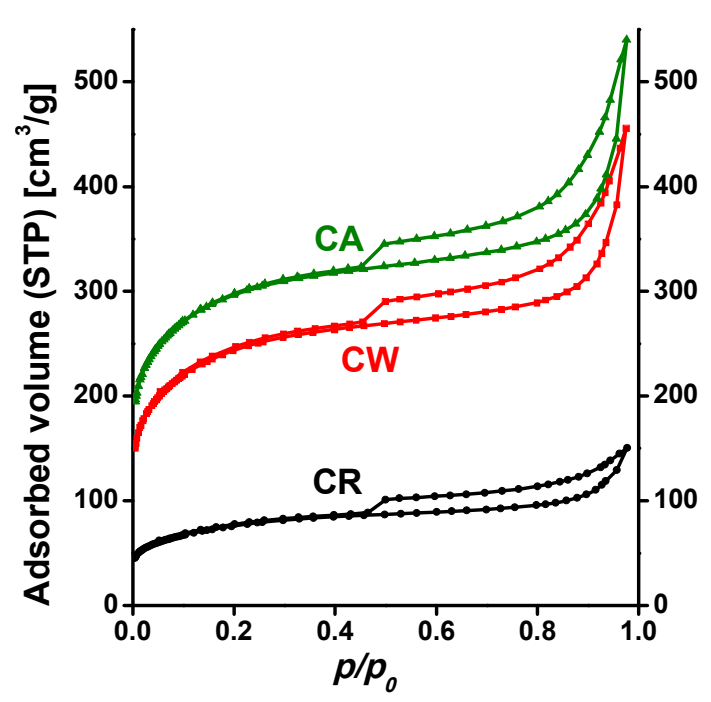

(a)

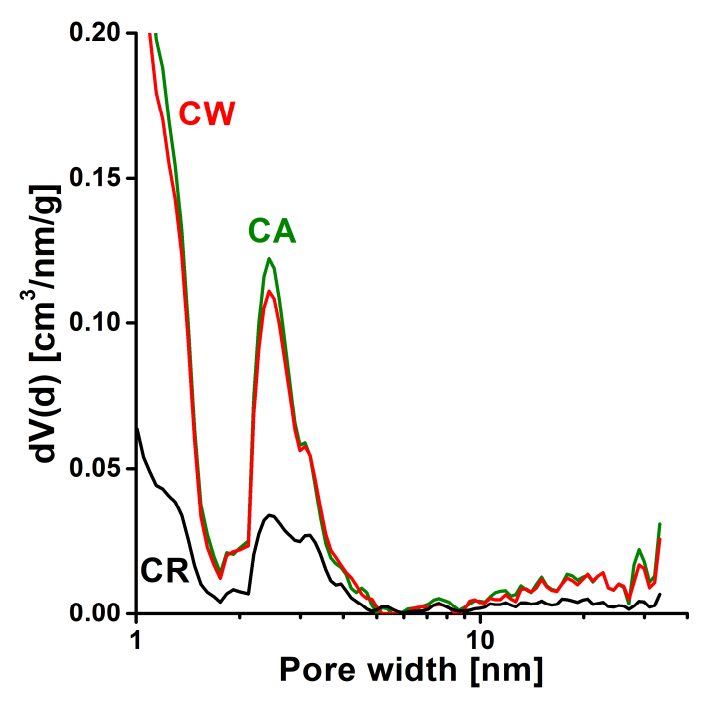

(b)

Figure 2. (a) Low temperature $\mathrm{N}_{2}$ adsorption/desorption isotherms; (b) Pore size distribution functions were estimated by quenched solid density functional theory (QSDFT) (Kernel: $\mathrm{N}_{2}$ at $77 \mathrm{~K}$ on carbon, slit/cylindrical pores, adsorption branch). 
The shape and the type of the hysteresis loop imply that the samples contain micro-, meso- and macropores that form an interconnected network. As the macropores are not completely filled with pore condensate, the total pore volume of the samples cannot be deduced from the nitrogen adsorption isotherms, instead, we estimated the liquid equivalent $V_{0.98}$ of the gas adsorbed at $p / p_{0}=0.98$. The development of the carbon texture during the synthesis steps is simultaneously revealed by the upward shift of the three isotherms, the pore size distribution curves (Figure 2b) and the XRD signals shown in the Supplementary Material Figure S2. The enhancement between CR and CW is related to the removal of inorganic minerals that survive the pyrolysis step, while the moderate shift from CW to CA results from the consecutive thermal treatment. The data deduced from the isotherms are shown in Table 1.

Table 1. Porous characteristics of carbon aerogel samples ${ }^{1}$.

\begin{tabular}{cccccc}
\hline Sample & $S_{\text {BET }}$ & $V_{\mathbf{0 . 9 8}}$ & \multicolumn{2}{c}{$V_{\text {micro }}$} \\
\hline \multicolumn{3}{c}{$\mathrm{m}^{2} / \mathrm{g}$} & \multicolumn{2}{c}{$\mathrm{cm}^{3} / \mathrm{g}$} & $\%$ \\
\hline $\mathrm{CR}$ & 272 & 0.23 & 0.10 & 42 \\
$\mathrm{CW}$ & 871 & 0.70 & 0.32 & 46 \\
$\mathrm{CA}$ & 1070 & 0.83 & 0.40 & 48 \\
\hline
\end{tabular}

${ }^{1}$ Apparent surface area from BET model, $V_{0.98}$ is the liquid equivalent of the gas adsorbed at $p / p_{0}=0.98$, and $V_{\text {micro }}$ refers to the micropore volume. $V_{\text {micro }}[\%]$ estimates the contribution of the adsorbed $\mathrm{N}_{2}$ filling the micropores.

The corresponding images in Figure 3 also confirm the changing morphology. The elemental mapping and apparent bulk composition of the three carbon samples (Figure S3, Table S1) indicate that $\mathrm{K}$ and $\mathrm{Ca}$ salts were removed during the acidic washing. The removal of the inorganic impurities and the development of the final CA texture can also be tracked from the Raman and FTIR spectra (Figure S4).
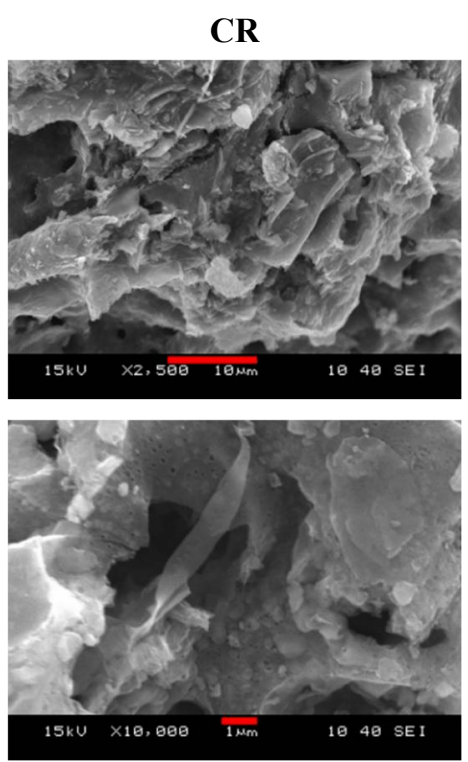

CW
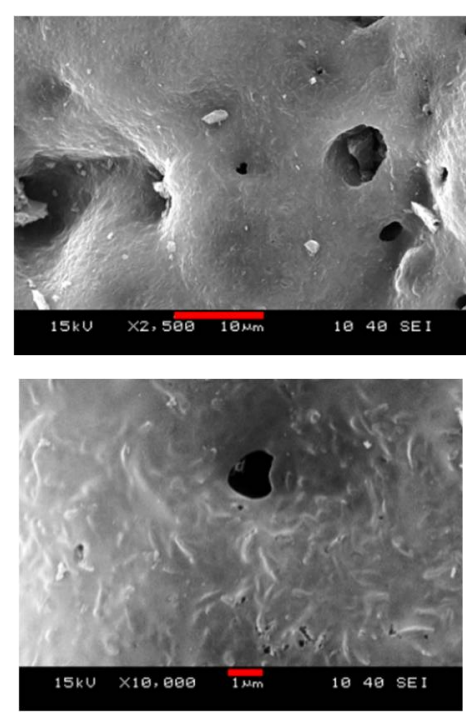

CA
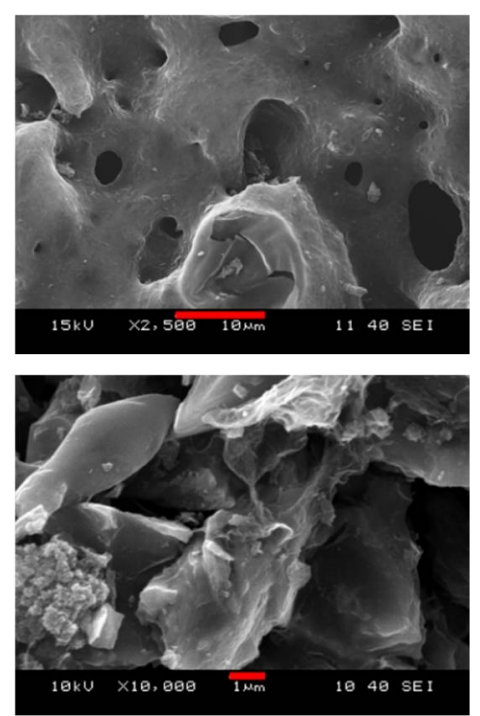

Figure 3. SEM images of carbon aerogel samples CR, CW, and CA. The scale bars are 10 and $1 \mu \mathrm{m}$ in the upper and lower raw, respectively.

The C1s, O1s, N1s and S2s regions of the XPS spectrum of the CA sample are shown in Figure 4. (Figure S5 shows the corresponding regions of the intermediate samples.) Although EDS is intrinsically less sensitive to low atomic number elements, the discrepancy between the EDS and XPS data (Table 2) indicates an inhomogeneous distribution of the nitrogen and sulfur. The concentrations of the metal impurities, $\mathrm{Na}$, $\mathrm{K}$ and $\mathrm{Ca}$, are below the detection limit of XPS, thus confirming the observations of the above mentioned methods. 


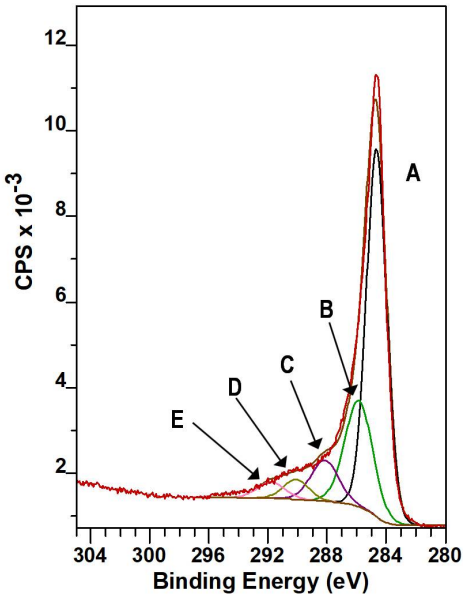

(C1s)

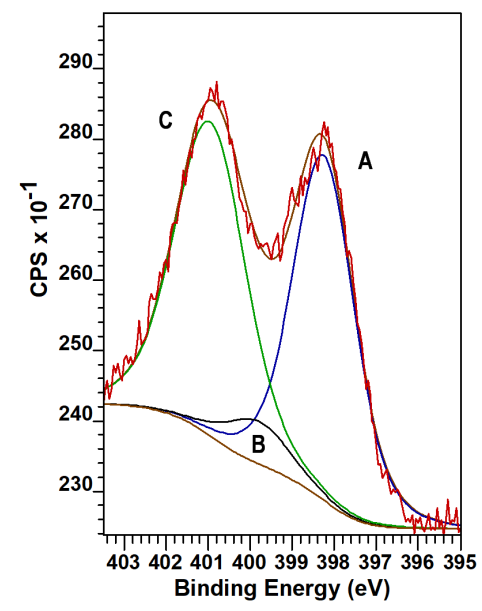

(N1s)

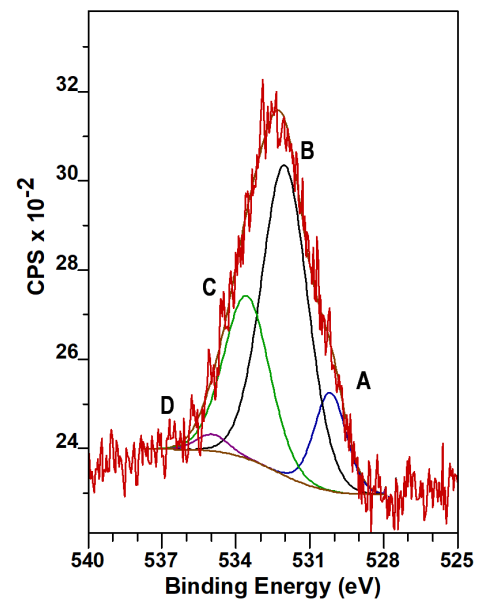

(O1s)

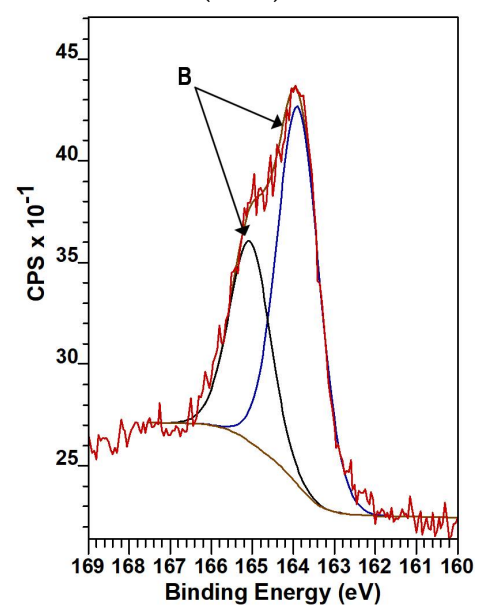

$(\mathrm{S} 2 \mathrm{p})$

Figure 4. Deconvoluted C1s, O1s, N1s and S2s regions of the CA sample.

Table 2. Surface compositions (atomic \%) measured by XPS.

\begin{tabular}{cccccccc}
\hline Sample & $\mathbf{C}$ & $\mathbf{O}$ & $\mathbf{N}$ & $\mathbf{S}$ & $\mathbf{K}$ & $\mathbf{C a}$ & $\mathbf{N a}$ \\
\hline CR & 67.2 & 20.5 & 5.9 & 0.5 & 2.1 & 3.2 & 0.6 \\
CW & 81.9 & 6.9 & 9.3 & 2.0 & n.d. ${ }^{*}$ & n.d. ${ }^{*}$ & n.d. \\
CA & 89.4 & 4.6 & 5.0 & 1.0 & n.d. ${ }^{*}$ & n.d. ${ }^{*}$ & n.d. ${ }^{*}$ \\
\hline
\end{tabular}

*n.d.: not detected.

The total $\mathrm{O}+\mathrm{N}+\mathrm{S}$ heteroatom/carbon ratio on the surface of the purified sample is close to $11 \%$, with practically an equal share of the $\mathrm{O}$ and $\mathrm{N}$ species. The species revealed by the deconvolution of the $\mathrm{C} 1 \mathrm{~s}, \mathrm{O} 1 \mathrm{~s}, \mathrm{~N} 1 \mathrm{~s}$ and $\mathrm{S} 2 \mathrm{p}$ regions were assigned according to Table S2. Based on the C1s and O1s regions, the surface of the CA carbon is decorated with carbonyl, epoxy, and carboxylic groups. Nitrogen in three different forms, namely in pyridinic, pyrrolic and quaternary, was detected. The S2p peak is split into 2p3/2 and $2 \mathrm{p} 1 / 2$ with $2: 1$ intensity and a $1.2 \mathrm{eV}$ binding energy gap. The double peak at around $163.8 \mathrm{eV}, 165 \mathrm{eV}$ shows the exclusive presence of thiophenic compounds in the final product.

The brief conclusion is that the purified CA carbon has a surface area of $1070 \mathrm{~m}^{2} / \mathrm{g}$ and a total pore volume of $0.83 \mathrm{~cm}^{3} / \mathrm{g}$. It contains $\mathrm{O}, \mathrm{N}$ and $\mathrm{S}$ heteroatoms at $4.6,5.0$ and 1.0 atomic $\%$, respectively. Based on these textural and surface chemical features this carbon is a promising candidate for gas adsorption and electrocatalysis applications. Without further optimization the gas storage performance was probed with $\mathrm{CO}_{2}, \mathrm{H}_{2}$ and methane, while the electrocatalytic properties of the CA carbon were tested in an oxygen reduction reaction. 


\subsection{Gas Storage Application}

$\mathrm{H}_{2}$ and $\mathrm{CH}_{4}$ were selected as they have considerably higher energy per unit mass in fuel application. Nevertheless, their low density at ambient temperature results in a poor energy per unit volume ratio. By enhancing the latter with adsorption-based gas storage technology could however open an avenue to them in portable power applications. At the same time, sorption related gas storage could offer a solution for reducing $\mathrm{CO}_{2}$ emission. The capture of $\mathrm{CO}_{2}$ produced in combustion processes and its storage could be an alternative to the present amine absorption process, which is hampered by several technical problems. Adsorption of $\mathrm{CO}_{2}$ by highly porous materials also could allow its large scale separation by the well-known pressure or temperature swing adsorption technologies [35]. As metal organic frameworks (MOFs) are among the materials with the greatest potential for sorption-based gas storage applications, copper benzene-1,3,5-tricarboxylate (HKUST1) synthesized in our laboratory was used as a comparison [36]. The $3 \mathrm{D}$ network of HKUST-1 incorporates pores of three well defined sizes of $0.5,1.1$ and $1.35 \mathrm{~nm}[37,38]$. The detailed characterization of the HKUST-1 used for comparison was presented in our previous work [39]. The almost exclusively microporous MOF sample was obtained from a solvothermal synthesis performed in an ethanol-water mixture. The apparent surface area $S_{B E T}$ and total pore volume are $1500 \mathrm{~m}^{2} / \mathrm{g}$ and $0.62 \mathrm{~cm}^{3} / \mathrm{g}$, respectively [39]. The former exceeds, while the latter remains below the corresponding values of CA (Table 1). As no kernel files necessary for DFT-based calculations are available, the pore size distribution of HKUST-1 was determined with the Barret-Joyner-Halenda (BJH) model [40]. However, this method underestimates the pore size of mesopores narrower than $\sim 10 \mathrm{~nm}$ by ca. $20-30 \%$ [34]. Nevertheless, the estimated distribution curve in Figure 5a clearly reflects the dual size distribution of this MOF in the supermicropore range, while its smallest pore size lies much beyond the limits of the method.

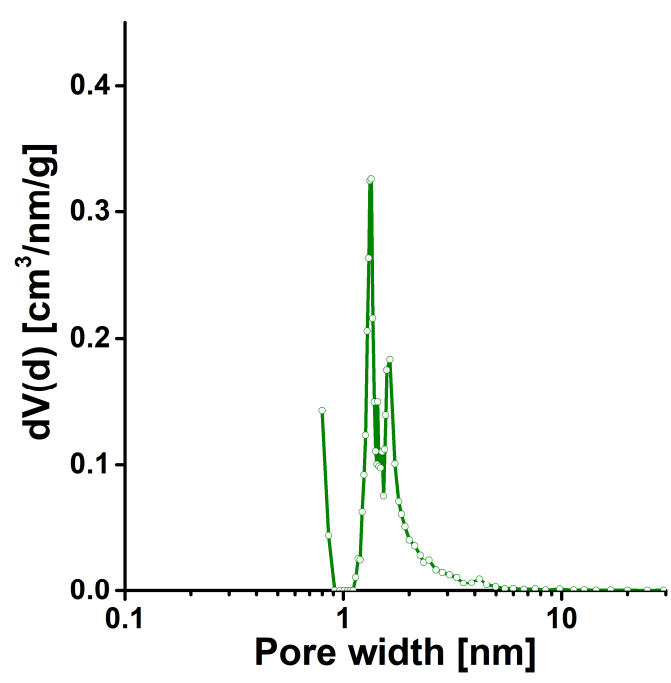

(a)

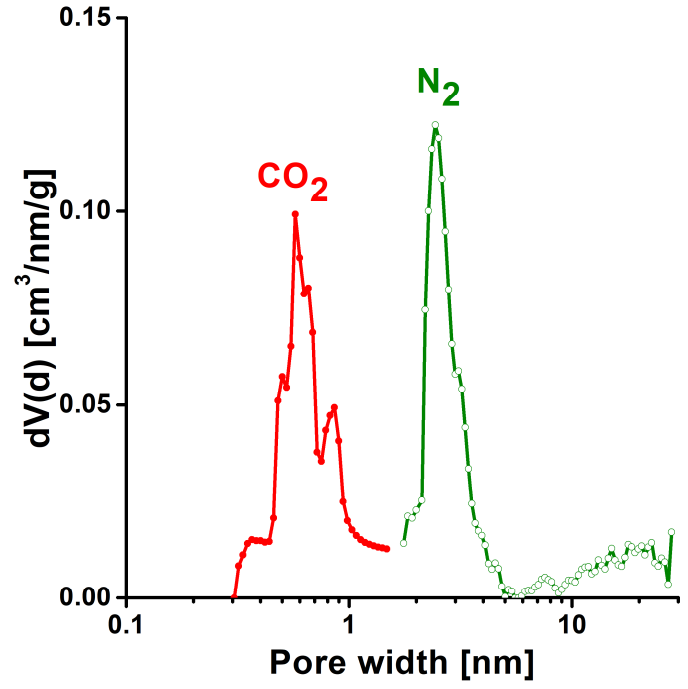

(b)

Figure 5. Pore size distribution of samples tested for gas storage. (a) HKUST-1, calculated with Barret-Joyner-Halenda (BJH) model [38]; (b) CA, derived from $\mathrm{CO}_{2}$ and $\mathrm{N}_{2}$ isotherms, calculated with QSDFT. Kernel: slit/cylindrical pores, adsorption branch.

Figure $5 \mathrm{~b}$ combines the pore size distribution curves of the CA sample obtained from $\mathrm{CO}_{2}$ and $\mathrm{N}_{2}$ isotherms with the QSDFT calculations. The curve computed from nitrogen data confirms the mesoporous character of $\mathrm{CA}$, as anticipated from the shape of the isotherm. In using $\mathrm{CO}_{2}$ as one of the test gases in this work, we take advantage of the fact that $\mathrm{CO}_{2}$ is also a frequently used gas to probe the pore size distribution of carbon materials. The higher kinetic energy of $\mathrm{CO}_{2}$ at the temperature of the isotherm 
measurements allows pores to be revealed that are inaccessible to nitrogen. Figure $5 b$ clearly shows that $\mathrm{CA}$ also possesses pores in the ultramicropore range.

Figure 6 shows the hydrogen, $\mathrm{CH}_{4}$ and $\mathrm{CO}_{2}$ adsorption isotherms of the $\mathrm{CA}$ samples up to atmospheric pressure. A recent publication reporting a new synthesis route of cellulose-based carbons has compared the atmospheric $\mathrm{CO}_{2}$ adsorption of several cellulosebased materials at $0{ }^{\circ} \mathrm{C}, 1 \mathrm{bar}$. The $3.64 \mathrm{mmol} / \mathrm{g}$ capacity of the CA sample falls into the $3.40-6.75 \mathrm{mmol} / \mathrm{g}$ range reported [6].

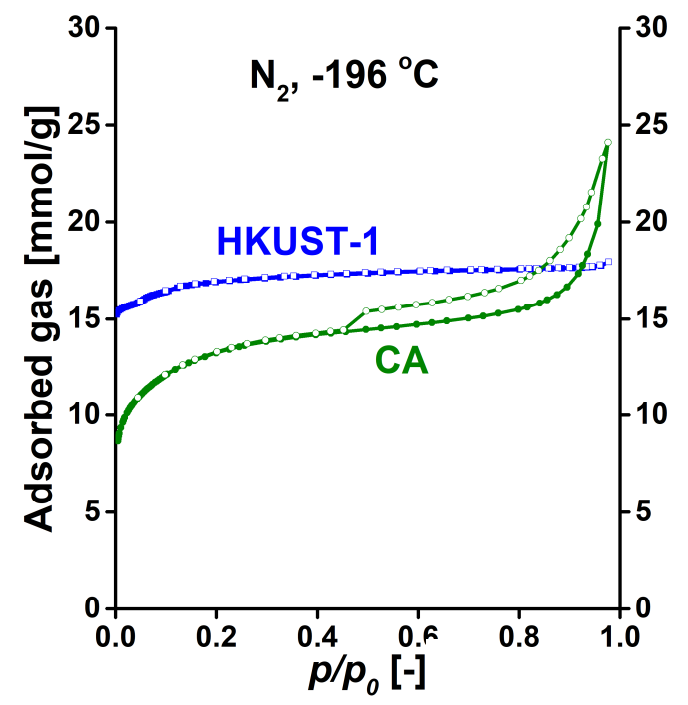

(a)

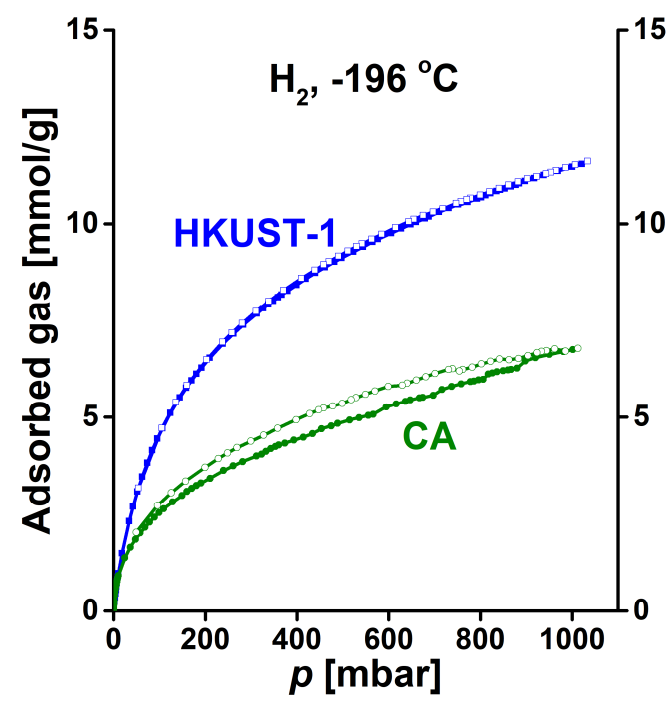

(c)

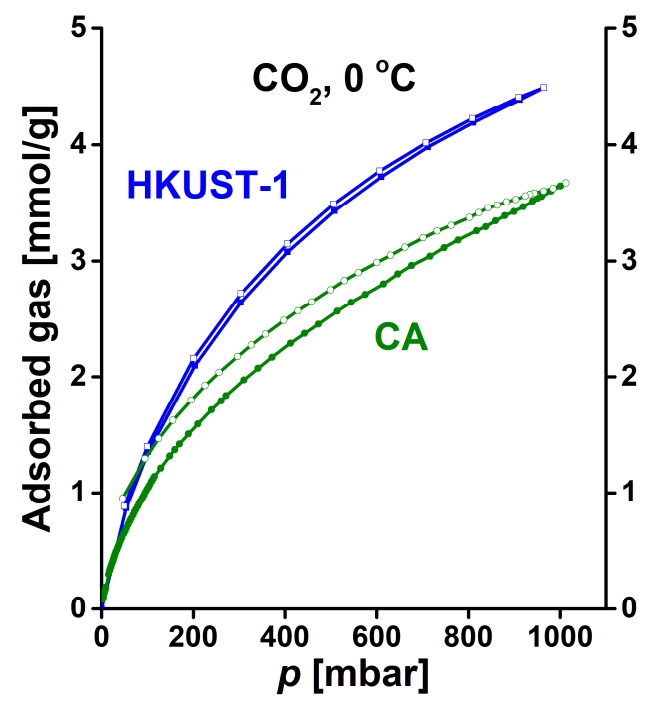

(b)

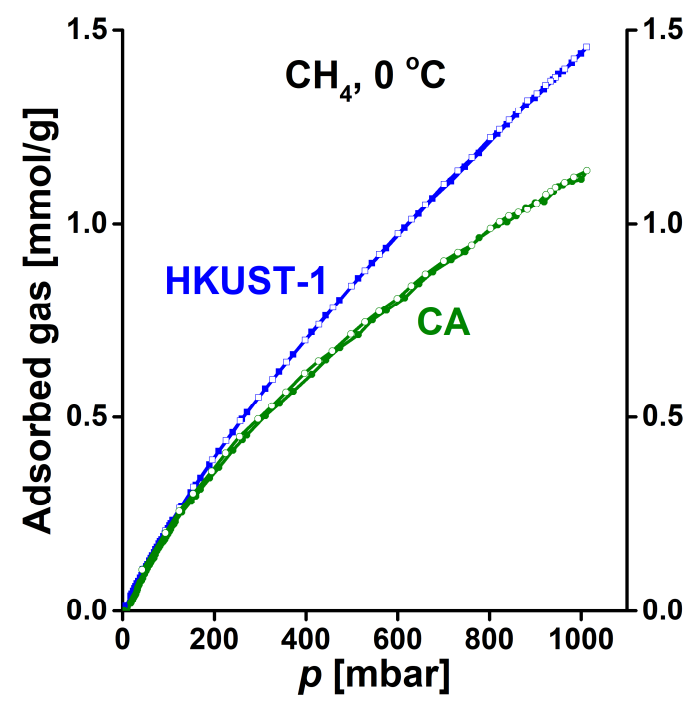

(d)

Figure 6. Comparison of adsorption isotherms of CA and HKUST-1 measured with (a) nitrogen, (b) carbon dioxide; (c) hydrogen; (d) methane.

While all the adsorption isotherms are practically reversible in HKUST-1, only $\mathrm{CH}_{4}$ shows a reversible adsorption on the CA. All the test gases, i.e., hydrogen, $\mathrm{CH}_{4}$ and $\mathrm{CO}_{2}$ exhibit a higher uptake on the MOF, but the deviation is more limited in case of the isotherms measured at $0{ }^{\circ} \mathrm{C}$. In high pressure applications the higher total pore volume of CA can lead to an improved performance.

The $\mathrm{CO}_{2}$ uptake of both porous materials is about four times higher than that of methane measured under the same conditions. This observation can be utilized in gas separation. As in Kamran et al. [6] the ideal adsorbed solution theory (IAST) [41] was 
applied to estimate and compare the $\mathrm{CO}_{2} / \mathrm{CH}_{4}$ selectivity of the samples. The initial sections of the isotherms were fitted to the linear Henry model. The full $\mathrm{CO}_{2}$ and $\mathrm{CH}_{4}$ adsorption isotherms of each material also gave a reasonable fit to the single-site LangmuirFreundlich model $[42,43]$

$$
n_{\text {ads }}=\frac{n_{\text {sat }} K p^{m}}{1+K p^{m}}
$$

where $n_{\text {ads }}$ is the quantity adsorbed at equilibrium pressure $p, n_{\text {sat }}$ is the saturation capacity, $K$ is the equilibrium constant of the Langmuir model and $m(>1)$ is the Freundlich exponent. The Henry constants $K_{H}$ for both gases and the calculated initial selectivity, as well as the fitted Langmuir-Freundlich parameters, are listed in Table 3.

Table 3. Parameters derived from Henry and Langmuir-Freundlich fits.

\begin{tabular}{|c|c|c|c|c|c|c|c|c|}
\hline \multirow{3}{*}{ Sample } & \multirow{3}{*}{ Gas } & \multicolumn{3}{|c|}{ Henry } & \multicolumn{4}{|c|}{ Langmuir-Freundlich } \\
\hline & & $K_{H}$ & $\mathbf{R}$ & $\frac{K_{H, \mathrm{CO}_{2}}}{K_{\mathrm{H}, \mathrm{CH}_{4}}}$ & $n_{\text {sat }}$ & $K$ & $m$ & $\mathbf{R}$ \\
\hline & & $\frac{\mathrm{mmol}}{\mathrm{g} \cdot \mathrm{mbar}}$ & & & $\frac{\mathrm{mmol}}{\mathrm{g}}$ & $\frac{1}{\text { mbar }}$ & & \\
\hline \multirow{2}{*}{ CA } & $\mathrm{CO}_{2}$ & 0.463 & 0.9974 & \multirow{2}{*}{10.5} & 12.5 & 0.00424 & 0.660 & 0.99987 \\
\hline & $\mathrm{CH}_{4}$ & 0.044 & 0.9963 & & 2.75 & 0.00088 & 0.963 & 0.99953 \\
\hline \multirow{2}{*}{ HKUST-1 } & $\mathrm{CO}_{2}$ & 0.232 & 0.9998 & \multirow{2}{*}{5.7} & 8.30 & 0.00485 & 0.799 & 0.99999 \\
\hline & $\mathrm{CH}_{4}$ & 0.041 & 0.9984 & & 7.01 & 0.00046 & 0.915 & 0.99997 \\
\hline
\end{tabular}

The selectivity for the $\mathrm{CO}_{2} / \mathrm{CH}_{4}$ gas mixture, calculated as

$$
S=\frac{n_{\mathrm{CO}_{2}} \cdot p_{\mathrm{CH}_{4}}}{n_{\mathrm{CH}_{4}} \cdot p_{\mathrm{CO}_{2}}}
$$

is shown in Figure 7. A semi-logarithmic pressure scale is used for clearer comparison.

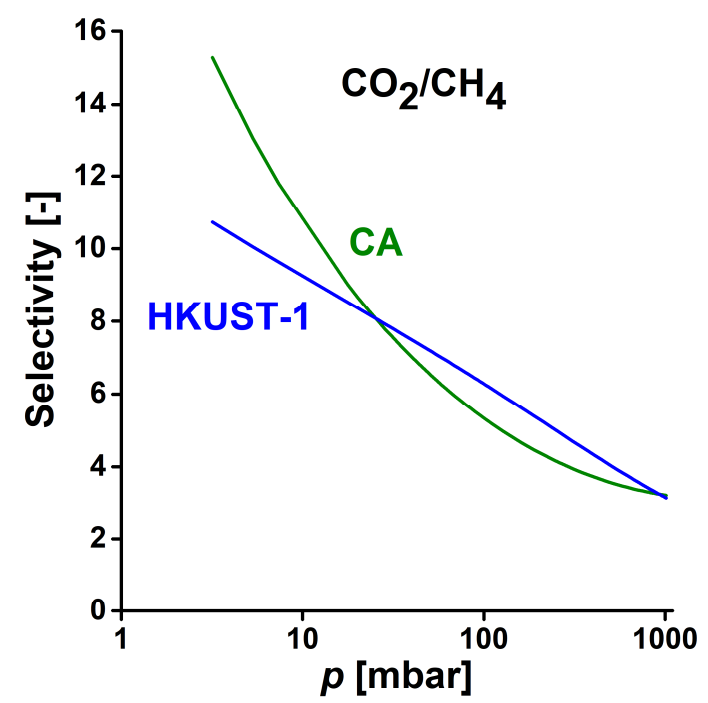

Figure 7. Comparison of the $\mathrm{CO}_{2} / \mathrm{CH}_{4}$ selectivity of CA and HKUST-1 from IAST using the Langmuir-Freundlich fit of the isotherms.

The selectivity of HKUST-1 in this representation displays a linear decrease. Increasing pressure also reduces the selectivity of CA monotonically, but in a more complex way. Below ca 20 bar the estimated selectivity of the carbon significantly exceeds that of the HKUST-1, then up to the upper limit of the pressure range investigated the MOF performs slightly better. That is in good agreement with the ratio of the Henry constants. This finding indicates that $\mathrm{CA}$ has potential applications in the separation of $\mathrm{CO}_{2}$ and methane from biogas. 


\subsection{Electrocatalytic Application}

The potential of CA as an electrode in the ORR and its electrochemical characteristics were investigated. The powdered electrode material was tested in a three-electrode cell configuration in $\mathrm{O}_{2}$ saturated $0.1 \mathrm{M} \mathrm{KOH}$ electrolyte. Figure 8 compares the results of the RDE measurements in the $\mathrm{O}_{2}$ saturated $0.1 \mathrm{M} \mathrm{KOH}$ on the $100 \mu \mathrm{g} / \mathrm{cm}^{2} \mathrm{CA}$ and a $20 \mathrm{wt} \%$ $\mathrm{Pt} / \mathrm{C}$ commercial electrode (Quintech): the performance of the CA electrode is similar to that of the $\mathrm{Pt} / \mathrm{C}$ electrode.

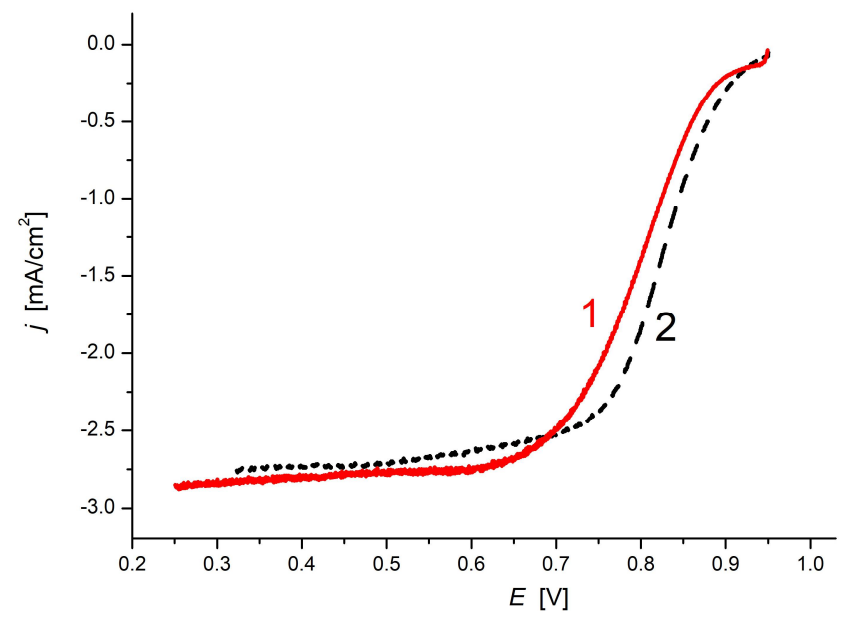

Figure 8. Linear potential sweep of CA sample (solid red line) and a $20 \mathrm{wt} \% \mathrm{Pt} / \mathrm{C}$ electrode (dashed black line) measured in $\mathrm{O}_{2}$ saturated $0.1 \mathrm{M} \mathrm{KOH}$ solution with a rotating disk electrode (1225 rpm). Loadings: $100 \mu \mathrm{g} / \mathrm{cm}^{2}$, Sweep rate: $5 \mathrm{mV} / \mathrm{s}$.

According to the results of the cyclic voltammetric measurements the specific gravimetric capacitance $\mathrm{Cg}$ of the CA electrode in $0.1 \mathrm{M} \mathrm{KOH}$ was approximately $377 \mathrm{~F} / \mathrm{g}$. This value was estimated from the anodic charge measured between 0.2 and $0.7 \mathrm{~V}$ (Figure 9). The $3.77 \mathrm{mC}$ corresponds to an electrode of geometrical surface area of $0.19625 \mathrm{~mm}^{2}$ loaded with $20 \mu \mathrm{g}$ catalyst, i.e., $100 \mu \mathrm{g} / \mathrm{cm}^{2}$ loading. These data indicate that the mass specific capacitance is roughly $377 \mathrm{~F} / \mathrm{g}$. This value is higher than the specific capacitance of several high performance electrode materials $[44,45]$ as shown in Table 4 . Comparison of the gravimetric capacitances listed in Table 3 leads us to the conclusion that practically only doped graphene and $\mathrm{B}$ containing carbons display a higher value than our biomass-based CA carbon. Note that carbon dots with double metal doping may exhibit much higher capacitance [46].

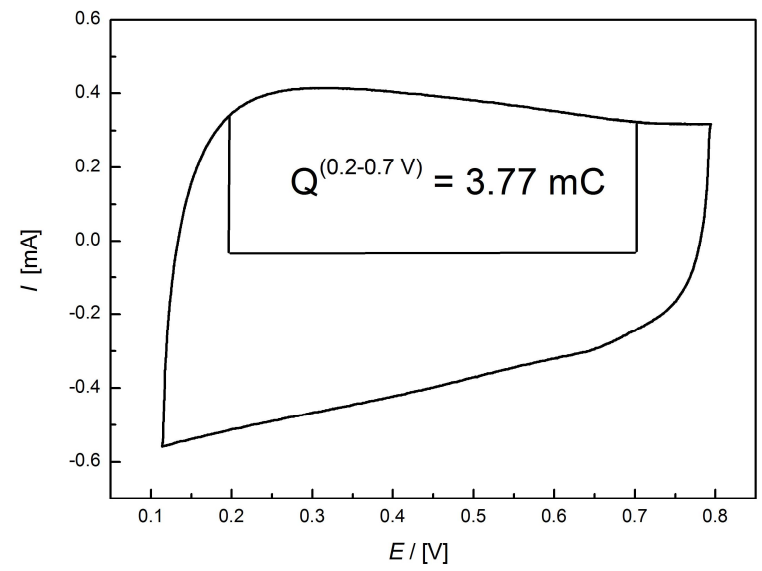

Figure 9. Cyclic voltammogram of the CA sample after ORR measurements. (Loadings: $100 \mu \mathrm{g} / \mathrm{cm}^{2}$, Sweep rate: $50 \mathrm{mV} / \mathrm{s}$.). 
Table 4. Gravimetric capacitance of dual doped metal free carbon materials in $\mathrm{KOH}$ electrolyte.

\begin{tabular}{lcr}
\hline \multicolumn{1}{c}{ Electrode Material } & $C_{g}$ & Reference \\
\hline & F/g & \\
\hline P/N co-doped ordered mesoporous carbon & 210 & {$[47]$} \\
N, P co-doped graphene & 219 & {$[48]$} \\
B, N co-doped graphene & 225 & {$[49]$} \\
N, S co-doped graphene & 264.3 & {$[50]$} \\
N, P dual-doped hierarchically porous carbon & 289 & {$[51]$} \\
N, S co-doped flexible graphene paper & 305 & {$[52]$} \\
N, S co-doped graphene oxide & 307 & {$[53]$} \\
3D N, S co-doped graphene hydrogel & 320 & {$[54]$} \\
N, S co-doped carbon & 322 & {$[55]$} \\
N, S co-doped porous carbon from ionic liquid precursor & 347 & {$[56]$} \\
N, S co-doped templated porous carbon & 367 & {$[57]$} \\
N, S co-doped biomass-based carbon aerogel (CA) & 377 & This work \\
N,S co-doped porous graphitic carbon from lotus leaves & 385 & {$[58]$} \\
B, N co-doped porous carbon foam & 402 & {$[59]$} \\
N, S co-doped graphene-enhanced hierarchical porous carbon foam & 405 & {$[60]$} \\
N, P co-doped high performance 3D graphene & 413 & {$[61]$} \\
N, S co-doped carbon (based on polymer from N and S containing & 461.5 & {$[62]$} \\
aromatic precursors) & 503 & {$[63]$} \\
N, S co-doped graphene material & 547 & {$[64]$} \\
Vertically-aligned BC2N nanotube arrays & 566 & {$[65]$} \\
N, S co-doped graphene & & \\
\hline
\end{tabular}

A 500-cycle preliminary stability test was carried out by cyclic polarization of a freshly prepared electrode in the potential range between 0.1 and $0.9 \mathrm{~V}$ relevant to ORR. After the 500 cycles only a slight increase of the surface (charge) was observed, as demonstrated in Figure 10.

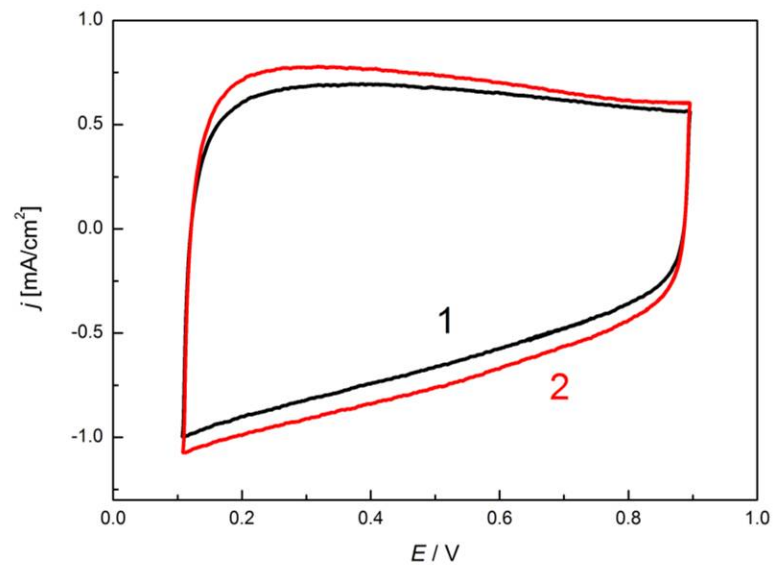

Figure 10. Cyclic voltammogram of a freshly prepared electrode in $0.1 \mathrm{M} \mathrm{KOH}(1)$, and after 500 cycles between potential limits 0.1 and $0.9 \mathrm{~V}(2)$.

The electrocatalytic properties were examined with a rotating disc electrode (RDE) in $0.1 \mathrm{M} \mathrm{KOH}$ electrolyte. The polarization curves at different potentials and rotation rates (400-1225 rpm) are shown in Figure 11a. The Koutecky-Levich (KL) equation was used to describe the correlation between the current densities and rotation rate

$$
\frac{1}{j}=\frac{1}{j_{k}}+\frac{1}{j_{l i m}}=\frac{1}{j_{k}}+\frac{1}{0.62 n F C D^{\frac{2}{3}} v^{-\frac{1}{6}} \omega^{1 / 2}}
$$

where $j$ is the current density, $j_{k}$ is the kinetic current density, $j_{\text {lim }}$ is the limiting diffusion current density, $n$ is the number of electrons transferred in ORR per oxygen molecule, $F$ 
is the Faraday constant, $D$ is the diffusion coefficient of oxygen in the electrolyte, $v$ is the kinematic viscosity of the electrolyte, $C$ is the concentration of oxygen in the electrolyte, and $w$ is the rotation rate in $\mathrm{rad} / \mathrm{s}[66]$.

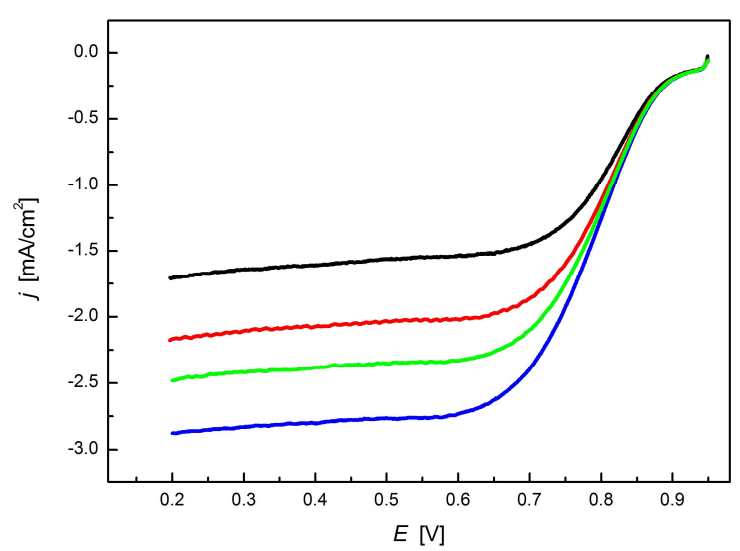

(a)

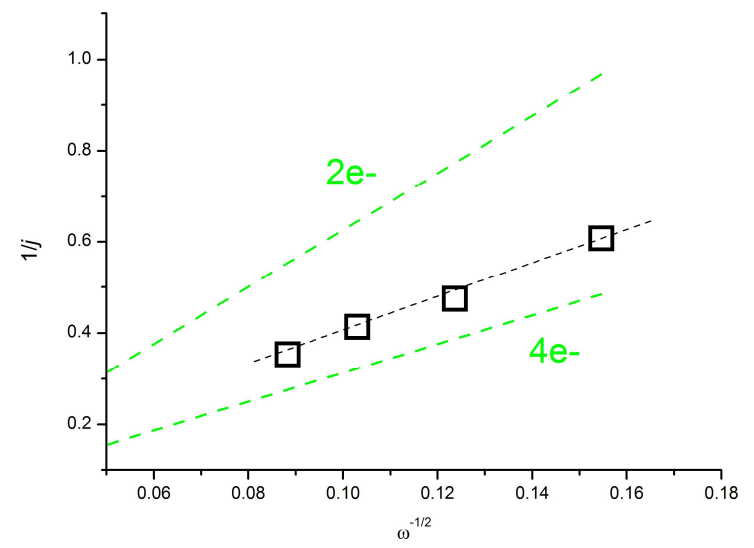

(b)

Figure 11. (a) Linear sweep voltammograms of CA sample $\left(100 \mu \mathrm{g} / \mathrm{cm}^{2}\right)$ measured in $\mathrm{O}_{2}$-saturated $0.1 \mathrm{M} \mathrm{KOH}$ solution with a rotating disk electrode (RDE). Rotation rates: 400 (black), 625 (red), 900 (green), $1225 \mathrm{rpm}$ (blue). Sweep rate: $5 \mathrm{mV} / \mathrm{s}$; (b) Koutecky-Levich plot from the linear sweep voltammetry responses at $0.30 \mathrm{~V}$. The theoretical KL slopes of the $2 \mathrm{e}^{-}$and $4 \mathrm{e}^{-}$routes are shown for comparison.

The oxygen reduction reaction in aqueous media occurs mainly through two different pathways. The four-electron reduction pathway transforms $\mathrm{O}_{2}$ directly to $\mathrm{H}_{2} \mathrm{O}$. The other route is a two-electron pathway through peroxide formation [67]. In polymer electrolyte membrane fuel cells (PEMFCs) the preferred ORR pathway is a four-electron transfer. Depending on the $\mathrm{pH}$ of the reaction media the $4 \mathrm{e}^{-}$reduction route has different thermodynamic potentials ranging from $0.401 \mathrm{~V}$ in alkaline media (Equation (4)) to $1.230 \mathrm{~V}$ in acidic media (Equation (5)) [67,68]:

$$
\begin{gathered}
\mathrm{O}_{2}+2 \mathrm{H}_{2} \mathrm{O}+4 \mathrm{e}^{-} \rightarrow 4 \mathrm{OH}^{-}(0.401 \mathrm{~V} \text { vs. standard hydrogen electrode, SHE }) \\
\mathrm{O}_{2}+4 \mathrm{H}^{+}+4 \mathrm{e}^{-} \rightarrow 2 \mathrm{H}_{2} \mathrm{O}(1.229 \mathrm{~V} \text { vs. SHE })
\end{gathered}
$$

The $2 \mathrm{e}^{-}$reduction follows a two-step mechanism. In basic media, the first step is shown in Equation (6). There are two possible reactions for the second step: a two-electron reduction of $\mathrm{HO}_{2}{ }^{-}$(Equation (7)) or its chemical disproportionation (Equation (8)) [68]:

$$
\begin{aligned}
\mathrm{O}_{2}+\mathrm{H}_{2} \mathrm{O}+2 \mathrm{e}^{-} & \rightarrow \mathrm{HO}_{2}^{-}(-0.076 \mathrm{~V} \text { vs. SHE }) \\
\mathrm{HO}_{2}^{-}+\mathrm{H}_{2} \mathrm{O}+2 \mathrm{e}^{-} & \rightarrow 3 \mathrm{HO}^{-}(0.878 \text { V vs. SHE }) \\
2 \mathrm{HO}_{2}^{-} & \rightarrow 2 \mathrm{HO}^{-}+\mathrm{O}_{2}
\end{aligned}
$$

In acidic media, the $2 \mathrm{e}^{-}$mechanism for ORR is shown by Equations (9) and (10):

$$
\begin{gathered}
\mathrm{O}_{2}+2 \mathrm{H}^{+}+2 \mathrm{e}^{-} \rightarrow 2 \mathrm{H}_{2} \mathrm{O}_{2}(0.695 \mathrm{~V} \text { vs. SHE }) \\
\mathrm{H}_{2} \mathrm{O}_{2}+2 \mathrm{H}^{+}+2 \mathrm{e}^{-} \rightarrow 2 \mathrm{H}_{2} \mathrm{O}(1.776 \text { V vs. SHE })
\end{gathered}
$$

The pore size distribution curves in Figure $5 \mathrm{~b}$ reveal that $\mathrm{CA}$ also possesses pores in the ultramicropore range. As has been recently pointed out, ultramicropores work as pseudocatalytic centers for ORR by promoting strong $\mathrm{O}_{2}$ adsorption. The thus facilitated $\mathrm{O}=\mathrm{O}$ bond splitting orientates the ORR through a $4 \mathrm{e}^{-}$reduction mechanism [26]. Figure $11 \mathrm{~b}$ implies that in case of CA the $4 \mathrm{e}^{-}$route is indeed the dominant pathway. 


\section{Conclusions}

A highly porous nanostructured carbon material was obtained from a marine biomassurea physical hydrogel. While $S$ is intrinsically contained in the carrageenan, urea was added as a nitrogen source during the synthesis process, yielding a $\mathrm{N}, \mathrm{S}$ double doped carbon material after pyrolysis. Aqueous $1.0 \mathrm{M} \mathrm{HCl}$ washing successfully removed the inorganic minerals of the carrageenan precursor that served also as an activating agent during the pyrolysis, thus giving access to fully or partially plugged voids. The final porous texture developed after high temperature annealing. The resulting CA carbon possesses a hierarchical pore system of micro-, meso- and macropores with an apparent surface area of $1070 \mathrm{~m}^{2} / \mathrm{g}$. XPS measurements showed that the total $\mathrm{O}, \mathrm{N}$ and $\mathrm{S}$ content of the final CA carbon was 4.6, 5.0 and 1.0 at $\%$, respectively, i.e., the heteroatom/carbon ratio was close to $11 \%$. The metal content was below the detection limit. While the $\mathrm{H}_{2}$ adsorption performance tested at $-196^{\circ} \mathrm{C}$ was exceeded by HKUST-1, the atmospheric $\mathrm{CO}_{2}$ and $\mathrm{CH}_{4}$ storage capacities at $0^{\circ} \mathrm{C}$ in the low pressure range were very similar to those of the MOF. The $\mathrm{CO}_{2} / \mathrm{CH}_{4}$ selectivity below 20 bar was even better in the CA, implying potential applications in biogas separation. In aqueous $\mathrm{KOH}$ medium the $\mathrm{CA}$ electrode exhibited almost the same performance as the commercial platinum loaded electrode used for comparison. The electrode displayed the 4-electron ORR mechanism and a promising stability in a 500-cycle preliminary test. On considering only metal free electrode materials, the specific gravimetric capacitance $377 \mathrm{~F} / \mathrm{g}$ of CA was exceeded only by B, N dual doped and/or graphene doped carbons.

Supplementary Materials: The following are available online at https:/ /www.mdpi.com/article/ 10.3390/ma14133488/s1, Figure S1: Figure S2: XRD diffractograms of the carbon aerogel samples. Figure S3: Elemental mapping from SEM-EDS analysis. Figure S4: (a) Baseline corrected and normalized Raman spectra. (b) FTIR spectra of the precursors and CA. Figure S5: Deconvoluted regions of the XPS spectra of the porous carbon intermediates. Table S1: Elemental compositions (atomic \%) measured by EDS. Table S2: Assignation of the chemical states in the C1s, O1s, N1s, and S2p $3 / 2$ regions.

Author Contributions: Conceptualization, K.L. and I.B.; methodology, G.D., A.F. and J.M.; formal analysis, G.K.; investigation, S.K.S.A. and S.K.; resources K.L. All authors have read and agreed to the published version of the manuscript.

Funding: This research was funded by the VEKOP-2.3.2-16-2017-00013 and 2020-3.1.1-ZFR-KVG2020-00006 projects. The VEKOP project is supported by the EU and by Hungary, co-financed by the European Regional Development Fund, while the 2020-3.1.2- ZFR-KVG program is supported by the National Research, Development and Innovation Office (NRDI). The work is also part of the EU project NANOMED (H2020-MSCA-RISE-2016, \#734641). The research was supported by the BME-Biotechnology (BME IE-BIO) TKP2020 IE grant. S.S.A. would like to thank the Stipendium Hungaricum scholarship program.

Institutional Review Board Statement: Not applicable.

Informed Consent Statement: Not applicable.

Data Availability Statement: Not applicable.

Acknowledgments: The authors are grateful to A. Domán and Gy. Bosznai for their help in SEM images and adsorption measurements, respectively. We thank the Soft Matters Group at Budapest University of Technology and Economics for access to their freeze drying facility.

Conflicts of Interest: The authors declare no conflict of interest.

\section{References}

1. Bar-On, Y.M.; Philips, R.; Milo, R. The biomass distribution on Earth. Proc. Natl. Acad. Sci. USA 2018, 115, 6506-6511. [CrossRef]

2. Gambles, R.; Zsuffa, L. The international energy agency-Cooperative research on biomass for energy. In Research in Thermochemical Biomass Conversion, 1st ed.; Bridgwater, A.V., Kuester, J.L., Eds.; Springer: Heidelberg, Germany, 1988.

3. Research and Markets. Available online: https://www.businesswire.com/news/home/20161124005116/en/GlobalCarrageenan-Market-Report-2015-2020 (accessed on 28 April 2021). 
4. Necas, J.; Bartosikova, L. Carrageenan: A review. Vet. Med. 2013, 58, 187-205. [CrossRef]

5. Michel, A.-S.; Mestdagh, M.M.; Axelos, M.A.V. Physico-chemical properties of carrageenan gels in presence of various cations. Int. J. Biol. Macromol. 1997, 21, 195-500. [CrossRef]

6. Kamran, U.; Park, S.J. Acetic acid-mediated cellulose-based carbons: Influence of activation conditions on textural features and carbon dioxide uptakes. J. Colloid Interface Sci. 2021, 594, 745-758. [CrossRef]

7. Zhao, S.; Liu, M.; Zhao, L.; Lu, J. Effects of organic and inorganic metal salts on thermogravimetric pyrolysis of biomass components. Korean J. Chem. Eng. 2017, 34, 3077-3084. [CrossRef]

8. Ilnicka, A.; Skorupska, M.; Tyc, M.; Kowalska, K.; Kamedulski, P.; Zielinski, W.; Lukaszewicz, J.P. Green algae and gelatine derived nitrogen rich carbon as an outstanding competitor to Pt loaded carbon catalysts. Sci. Rep. 2021, 11, 7084. [CrossRef] [PubMed]

9. Ubaidullah., M.; Al-Enizi, A.M.; Ahamad, T.F.; Shaikh, S.F.; Al-Abdrabalnabi, M.A.; Samdani, M.S.; Kumar, D.; Alam, M.A.; Khan, M. N-doped mesoporous carbon using waste polyethylene terephthalate bottle-based MOF-5 for high performance supercapacitor. J. Energy Storage 2021, 33, 102125. [CrossRef]

10. Zhang, J.; Zhang, J.; He, F.; Chen, J.; Wang, D.; Shichun, M.; Yang, H.Y. Defect and doping co-engineered non-metal nanocarbon ORR electrocatalyst. Nano-Micro Lett. 2021, 13, 65. [CrossRef]

11. Yang, Z.; Yao, Z.; Li, G.; Fang, G.; Nie, H.; Liu, Z.; Zhou, X.; Chen, X.; Huang, S. Sulfur-doped graphene as an efficient metal-free cathode catalyst for oxygen reduction. ACS Nano 2012, 6, 205-211. [CrossRef] [PubMed]

12. Zhang, L.; Niu, J.; Li, M.; Xia, Z. Catalytic mechanisms of sulfur-doped graphene as efficient oxygen reduction reaction catalysts for fuel cells. J. Phys. Chem. C 2014, 118, 3545-3553. [CrossRef]

13. Seredych, M.; László, K.; Bandosz, T. Sulfur-doped carbon aerogel as a metal-free oxygen reduction catalyst. ChemCatChem 2015, 7, 2924-2931. [CrossRef]

14. Seredych, M.; Biggs, M.; Bandosz, T. Oxygen reduction on chemically heterogeneous iron-containing nanoporous carbon: The effects of specific surface functionalities. Micropor. Mesopor. Mater. 2016, 221, 137-149. [CrossRef]

15. Voitko, K.; Tóth, A.; Demianenko, E.; Dobos, G.; Berke, B.; Bakalinska, O.; Grebenyuk, A.; Tombácz, E.; Kuts, V.; Tarasenko, Y.; et al. Catalytic performance of carbon nanotubes in $\mathrm{H}_{2} \mathrm{O}_{2}$ decomposition: Experimental and quantum chemical study. J. Colloid Interface Sci. 2015, 437, 283-290. [CrossRef]

16. Nagy, B.; Bakos, I.; Bertóti, I.; Domán, A.; Menyhárd, A.; Mohai, M.; László, K. Synergism of nitrogen and reduced graphene in the electrocatalytic behavior of resorcinol-Formaldehyde based carbon aerogels. Carbon 2018, 139, 872-879. [CrossRef]

17. Zhu, J.; Xiao, M.; Song, P.; Fu, J.; Jin, Z.; Ma, L.; Ge, J.; Liu, C.; Chen, Z.; Xing, W. Highly polarized carbon nano-architecture as robust metal-free catalyst for oxygen reduction in polymer electrolyte membrane fuel cells. Nano Energy 2018, 49, 23-30. [CrossRef]

18. Bertóti, I.; Mohai, M.; László, K. Surface modification of graphene and graphite by nitrogen plasma: Determination of chemical state alterations and assignments by quantitative X-ray photoelectron spectroscopy. Carbon 2015, 84, 185-196. [CrossRef]

19. Guo, D.; Shibuya, R.; Akiba, C.; Saji, S.; Kondo, T.; Nakamura, J. Active sites of nitrogen-doped carbon materials for oxygen reduction reaction clarified using model catalysts. Science 2016, 351, 361-365. [CrossRef] [PubMed]

20. Yang, J.; Zhou, X.; Wu, D.; Zhao, X.; Zhou, Z. S-doped N-rich carbon nanosheets with expanded interlayer distance as anode materials for sodium-ion batteries. Adv. Mater. 2017, 29, 1604108. [CrossRef] [PubMed]

21. Ai, W.; Luo, Z.; Jiang, J.; Zhu, J.; Du, Z.; Fan, Z.; Xie, L.; Zhang, H.; Huang, W.; Yu, T. Nitrogen and sulfur codoped graphene: Multifunctional electrode materials for high-performance Li-ion batteries and oxygen reduction reaction. Adv. Mater. 2014, 26, 6186-6192. [CrossRef]

22. Duan, X.; O'Donnell, K.; Sun, H.; Wang, Y.; Wang, S. Sulfur and Nitrogen co-doped graphene for metal-free catalytic oxidation reactions. Small 2015, 11, 3036-3044. [CrossRef] [PubMed]

23. Zhao, H.; Weng, C.C.; Hu, Z.P.; Ge, L.; Yuan, Z.Y. CdS-polydopamine-derived N, S-codoped hierarchically porous carbons as highly active electrocatalyst for oxygen reduction. ACS Sustain. Chem. Eng. 2017, 5, 9914-9922. [CrossRef]

24. Jia, Q.; Yang, C.; Pan, Q.; Xin, Y.; Xu, F.; Qi, W.; Wei, H.; Yang, S.; Zhou, C.; Hu, N.; et al. High-voltage aqueous asymmetric pseudocapacitors based on methyl blue-doped polyaniline hydrogels and the derived N/S-codoped carbon aerogels. Chem. Eng. J. 2020, 383, 123153. [CrossRef]

25. Liang, J.; Jiao, Y.; Jaroniec, M.; Qiao, S.Z. Sulfur and nitrogen dual-doped mesoporous graphene electrocatalyst for oxygen reduction with synergistically enhanced performance. Angew. Chem. Int. Ed. 2012, 51, 11496-11500. [CrossRef]

26. De Falco, G.; Florent, M.; Jagiello, J.; Cheng, Y.; Daemen, L.L.; Ramirez-Cuesta, A.J.; Bandosz, T.J. Alternative view of oxygen reduction on porous carbon electrocatalysts: The substance of complex oxygen-surface interactions. iScience 2021, $24,102216$. [CrossRef] [PubMed]

27. Li, D.; Li, W.B.; Shi, J.S.; Xin, F.W. Influence of doping nitrogen, sulfur, and phosphorus on activated carbons for gas adsorption of $\mathrm{H}_{2}, \mathrm{CH}_{4}$ and $\mathrm{CO}_{2}$. RSC Adv. 2016, 6, 50138-50143. [CrossRef]

28. Sánchez-Sánchez, A.; Suárez-García, F.; Martínez-Alonso, A.; Tascón, J.M.D. Influence of porous texture and surface chemistry on the $\mathrm{CO}_{2}$ adsorption capacity of porous carbons: Acidic and basic site interactions. ACS Appl. Mater. Interfaces 2014, 6, 21237-21247. [CrossRef]

29. Wang, D.; Shen, Y.; Chen, Y.; Liu, L.; Zhao, Y. Microwave-assistant preparation of N/S co-doped hierarchical porous carbons for hydrogen adsorption. Chem. Eng. J. 2019, 367, 260-268. [CrossRef] 
30. Li, D.; Jia, Y.; Chang, G.; Chen, J.; Liu, H.; Wang, J.; Hu, Y.; Xia, Y.; Yang, D.; Yao, X. A defect-driven metal-free electrocatalyst for oxygen reduction in acidic electrolyte. Chem 2018, 4, 2345-2356. [CrossRef]

31. Brunauer, S.; Emmett, P.H.; Teller, E. Adsorption of gases in multimolecular layers. J. Am. Chem. Soc. 1938, 60, 309-319. [CrossRef]

32. Dubinin, M.M. The equation of the characteristic curve of activated charcoal. Dokl. Akad. Nauk. 1947, 55, 327-329.

33. Landers, J.; Gor, G.Y.; Neimark, A.V. Density functional theory methods for characterization of porous materials. Colloids Surf. A Physicochem. Eng. Asp. 2013, 437, 3-32. [CrossRef]

34. Thommes, M.; Kaneko, K.; Neimark, A.V.; Olivier, J.P.; Rodriguez-Reinoso, F.; Rouquerol, J.; Sing, K.S.W. Physisorption of gases, with special reference to the evaluation of surface area and pore size distribution (IUPAC Technical Report). Pure Appl. Chem. 2015, 87, 1051-1069. [CrossRef]

35. Kaneko, K.; Rodríguez-Reinoso, F. Nanoporous Materials for Gas Storage, 1st ed.; Springer: Singapore, 2019 ; p. 403.

36. Li, H.; Li, L.; Lin, R.B.; Zhou, W.; Zhang, Z.; Xiang, S.; Chen, B. Porous metal-organic frameworks for gas storage and separation: Status and challenges. EnergyChem 2019, 1, 100006. [CrossRef]

37. Worrall, S.D.; Bissett, M.A.; Hill, P.I.; Rooney, A.P.; Haigh, S.J.; Attfield, M.P.; Dryfe, R.A.W. Metal-organic framework templated electrodeposition of functional gold nanostructures. Electrochim. Acta 2016, 222, 361-369. [CrossRef]

38. Gotthardt, M.A.; Schoch, R.; Wolf, S.; Bauer, M.; Kleist, W. Synthesis and characterization of bimetallic metal-organic framework Cu-Ru-BTC with HKUST-1 structure. Dalton Trans. 2015, 44, 2052-2056. [CrossRef]

39. Domán, A.; Madarász, J.; Sáfrán, G.; Wang, Y.; László, K. Copper benzene-1,3,5-tricarboxylate (HKUST-1)-graphene oxide pellets for methane adsorption. Microporous Mesoporous Mater. 2021, 316, 110948. [CrossRef]

40. Barret, E.P.; Joyner, L.G.; Halenda, P.P. The determination of pore volume and area distributions in porous substances. Computations from nitrogen isotherms. J. Am. Chem. Soc. 1951, 73, 373-380. [CrossRef]

41. Myers, A.L.; Prausnitz, J.M. Thermodynamics of mixed-gas adsorption. AIChE J. 1965, 11, 121-127. [CrossRef]

42. Sips, R. On the structure of a catalyst surface. J. Chem. Phys. 1948, 16, 490-495. [CrossRef]

43. Sips, R. On the structure of a catalyst surface. II. J. Chem. Phys. 1950, 18, 1024-1026. [CrossRef]

44. Feng, X.; Bai, Y.; Liu, M.; Li, Y.; Yang, H.; Wang, X.; Wu, C. Untangling the respective effects of heteroatom-doped carbon materials in batteries, supercapacitors and the ORR to design high performance materials. Energy Environ. Sci. 2021, 14, 2036. [CrossRef]

45. Kumari, S.; Verma, E.; Kumar, R.; Upreti, D.; Prakash, B.; Maruyama, T.; Bagchi, V. Micropores within N,S co-doped mesoporous 3D graphene-aerogel enhance the supercapacitive performance. New J. Chem. 2021, 45, 7523-7532. [CrossRef]

46. Al-Enizi, A.M.; Ubaidullah, M.; Kumar, D. Carbon quantum dots (CQDs)/Ce doped NiO nanocomposite for high performance supercapacitor. Mater. Today Commun. 2021, 27, 10234.

47. Panja, T.; Bhattacharjya, D.; Yu, J.S. Nitrogen and phosphorus co-doped cubic ordered mesoporous carbon as a supercapacitor electrode material with extraordinary cyclic stability. J. Mater. Chem. A 2015, 3, 18001-18009. [CrossRef]

48. Xia, K.; Huang, Z.; Zheng, L.; Han, B.; Gao, Q.; Zhou, C.; Wang, H.; Wu, J. Facile and controllable synthesis of N/P co-doped graphene for high-performance supercapacitors. J. Power Sources 2017, 365, 380-388. [CrossRef]

49. Chen, Z.; Hou, L.; Cao, Y.; Tang, Y.; Li, Y. Gram-scale production of B, N co-doped graphene-like carbon for high performance supercapacitor electrodes. Appl. Surf. Sci. 2018, 435, 937-944. [CrossRef]

50. Tian, P.; Zang, J.; Jia, S.; Zhang, Y.; Gao, H.; Zhou, S.; Wang, W.; Xu, H.; Wang, Y. Preparation of S/N co-doped graphene through a self-generated high gas pressure for high rate supercapacitor. Appl. Surf. Sci. 2018, 456, 781-788. [CrossRef]

51. Shang, N.; Gao, S.; Zhang, X.; Zhang, S.; Feng, C.; Wang, Z.; Wang, C. N,P dual-doped hierarchically porous carbon derived from a polyelectrolyte complex as high-performance electrodes for supercapacitors. Energy Technol. 2019, 7, 1800641. [CrossRef]

52. Akhter, T.; Islam, M.; Faisal, S.N.; Haque, E.; Minett, A.I.; Liu, H.K.; Konstantinov, K.; Dou, S.X. Self-assembled N/S codoped flexible graphene paper for high performance energy storage and oxygen reduction reaction. ACS Appl. Mater. Interfaces 2016, 8 , 2078-2087. [CrossRef]

53. Miao, Y.; Ma, Y.; Wang, Q. Plasma-assisted simultaneous reduction and nitrogen/sulfur codoping of graphene oxide for high-performance supercapacitors. ACS Sustain. Chem. Eng. 2019, 7, 7597-7608. [CrossRef]

54. Kong, W.; Zhu, J.; Zhang, M.; Liu, Y.; Hu, J. Three-dimensional N- and S- codoped graphene hydrogel with in-plane pores for high performance supercapacitor. Microporous Mesoporous Mater. 2018, 268, 260-267. [CrossRef]

55. Liu, M.; Huo, S.; Xu, M.; Wu, L.; Liu, M.; Xue, Y.; Yan, Y.M. Structural engineering of N/S co-doped carbon material as high-performance electrode for supercapacitors. Electrochim. Acta 2018, 274, 389-399. [CrossRef]

56. Sun, L.; Yao, Y.; Zhou, Y.; Li, L.; Zhou, H.; Guo, M.; Liu, S.; Feng, C.; Qi, Z.; Gao, B. Solvent-free synthesis of N/S-codoped hierarchically porous carbon materials from protic ionic liquids for temperature-resistant, flexible supercapacitors. ACS Sustain. Chem. Eng. 2018, 6, 13494-13503. [CrossRef]

57. Yang, W.; Yang, W.; Song, A.; Gao, L.; Su, L.; Shao, G. Supercapacitance of nitrogen-sulfur-oxygen co-doped 3D hierarchical porous carbon in aqueous and organic electrolyte. J. Power Sources 2017, 359, 556-567. [CrossRef]

58. Wan, L.; Li, N.; Li, X.; Chen, J.; Zhang, Y.; Xie, M.; Du, C. One-step synthesis of N, S-codoped porous graphitic carbon derived from lotus leaves for high-performance supercapacitors. Ionics 2019, 25, 4891-4903. [CrossRef]

59. Guo, D.; Ding, B.; Hu, X.; Wang, Y.; Han, F.; Wu, X. Synthesis of Boron and Nitrogen Codoped Porous Carbon Foam for High Performance Supercapacitors. ACS Sustain. Chem. Eng. 2018, 6, 11441-11449. [CrossRef]

60. Ma, L.; Liu, J.; Lv, S.; Zhou, Q.; Shen, X.; Mo, S.; Tong, H. Scalable one-step synthesis of N,S co-doped graphene-enhanced hierarchical porous carbon foam for high-performance solid-state supercapacitors. J. Mater. Chem. A 2019, 7, 7591-7603. [CrossRef] 
61. Zhao, Y.; Huang, S.; Xia, M.; Rehman, S.; Mu, S.; Kou, Z.; Zhang, Z.; Chen, Z.; Gao, F.; Hou, Y. N-P-O co-doped high performance 3D graphene prepared through red phosphorous-assisted "cutting-thin" technique: A universal synthesis and multifunctional applications. Nano Energy 2016, 28, 346-355. [CrossRef]

62. Lu, H.; Yang, C.; Chen, J.; Li, J.; Jin, H.; Wang, J.; Wang, S. Tailoring hierarchically porous nitrogen-, sulfur-, codoped carbon for high-performance supercapacitors and oxygen reduction. Small 2020, 16, 1906584. [CrossRef]

63. Wadekar, P.H.; Khose, R.V.; Pethsangave, D.A.; Some, S. One-pot synthesis of sulfur and nitrogen co-functionalized graphene material using deep eutectic solvents for supercapacitors. ChemSusChem 2019, 12, 3326-3335. [CrossRef]

64. Zhou, J.; Li, N.; Gao, F.; Zhao, Y.; Hou, L.; Xu, Z. Vertically-aligned BCN Nanotube Arrays with Superior Performance in Electrochemical capacitors. Sci. Rep. 2014, 4, 6083. [CrossRef]

65. Wang, T.; Wang, L.X.; Wu, D.L.; Xia, W.; Jia, D.Z. Interaction between nitrogen and sulfur in co-doped graphene and synergetic effect in supercapacitor. Sci. Rep. 2015, 5, 9591. [CrossRef] [PubMed]

66. Chandran, P.; Ghosh, A.; Ramaprabhu, S. High-performance Platinum-free oxygen reduction reaction and hydrogen oxidation reaction catalyst in polymer electrolyte membrane fuel cell. Sci. Rep. 2018, 8, 3591. [CrossRef] [PubMed]

67. Khotseng, L. Oxygen reduction reaction. In Electrocatalysts for Fuel Cells and Hydrogen Evolution-Theory to Design, 1st ed.; Ray, A., Mukhopadhyay, I., Pati, R.K., Eds.; IntechOpen: Rijeka, Croatia, 2018.

68. Ma, R.; Lin, G.; Zhou, Y.; Liu, Q.; Zhang, T.; Shan, G.; Yang, M.; Wang, J. A review of oxygen reduction mechanisms for metal-free carbon-based electrocatalysts. NPJ Comput. Mater. 2019, 5, 78. [CrossRef] 